\title{
Quantitating the Specificity and Selectivity of Gen5-Mediated Acetylation of Histone H3
}

\author{
Yin-Ming Kuo, Andrew J. Andrews* \\ Department of Cancer Biology, Fox Chase Cancer Center, Philadelphia, Pennsylvania, United States of America
}

\begin{abstract}
Lysine acetyltransferases (KATs) play a unique role in regulating gene transcription as well as maintaining the epigenetic state of the cell. KATs such as Gcn5 and p300/CBP can modify multiple residues on a single histone; however, order and specificity of acetylation can be altered by factors such as histone chaperones, subunit proteins or external stimulus. While the importance of acetylation is well documented, it has been difficult to quantitatively measure the specificity and selectivity of acetylation at different residues within a histone. In this paper, we demonstrate a label-free quantitative high throughput mass spectrometry-based assay capable of quantitatively monitoring all known acetylation sites of $\mathrm{H} 3$ simultaneously. Using this assay, we are able to analyze the steady-state enzyme kinetics of Gcn5, an evolutionarily conserved KAT. In doing so, we measured Gcn5-mediated acetylation at six residues (K14>K9 $\approx \mathrm{K} 23>\mathrm{K} 18>\mathrm{K} 27 \approx \mathrm{K} 36)$ and the catalytic efficiency $\left(\mathrm{k}_{\mathrm{cat}} / \mathrm{K}_{\mathrm{m}}\right)$ for $\mathrm{K} 9, \mathrm{~K} 14, \mathrm{~K} 18$, and $\mathrm{K} 23$ as well as the nonenzymatic acetylation rate. We observed selectivity differences of up to $-4 \mathrm{kcal} / \mathrm{mol}$ between $\mathrm{K} 14$ and $\mathrm{K} 18$, the highest and lowest measurable $\mathrm{k}_{\text {cat }} / \mathrm{K}_{\mathrm{m}}$. These data provide a first look at quantitating the specificity and selectivity of multiple lysines on a single substrate $(\mathrm{H} 3)$ by $\mathrm{Gcn} 5$.
\end{abstract}

Citation: Kuo Y-M, Andrews AJ (2013) Quantitating the Specificity and Selectivity of Gcn5-Mediated Acetylation of Histone H3. PLoS ONE 8(2): e54896. doi:10.1371/ journal.pone.0054896

Editor: Annalisa Pastore, National Institute for Medical Research, Medical Research Council, United Kingdom

Received October 25, 2012; Accepted December 17, 2012; Published February 21, 2013

Copyright: (c) 2013 Kuo, Andrews. This is an open-access article distributed under the terms of the Creative Commons Attribution License, which permits unrestricted use, distribution, and reproduction in any medium, provided the original author and source are credited.

Funding: This project is funded, in part, under a grant with the Pennsylvania Department of Health. The Pennsylvania Department of Health specifically disclaims responsibility for any analysis, interpretations or conclusions. The funders had no role in study design, data collection and analysis, decision to publish, or preparation of the manuscript. No additional external funding was received for this study.

Competing Interests: The authors have declared that no competing interests exist.

* E-mail: Andrew.Andrews@fccc.edu

\section{Introduction}

Many of the major human diseases, from cancer to heart disease, correlate with global changes in the identity and residue location of histone post-translational modifications (PTMs), supporting their central roles in maintaining the epigenetic state of the cell [1-4]. Changes in global acetylation patterns result from the diverse functions of histone or lysine acetyltransferases $(\mathrm{KATs})$ $[5,6]$. KATs play active roles in transcription, marking locations of DNA repair, and correlating to changes in the cell cycle $[7,8]$. While the importance of the changes to the location and amount of acetylation and other modifications that make up the histone code is well supported $[1,9,10]$, we have a limited understanding of how it is written.

Complicating our understanding of how the histone code is written is that many of the characterized KATs can modify histones at multiple lysines on a single histone. Both p300/CBP (KAT3A/B) and Gen5 (KAT2A) acetylate multiple lysines on histone $\mathrm{H} 3$ [11-16]. The primary site of acetylation by Gen5 is H3K14, but other specific sites are also modified, such as H3K9, H3K18, H3K23, and H3K27 [17]. Despite their critical importance, little is known about the specificity of Gcn5 for acetylation at lysine sites other than H3K14. Additionally, the field has been limited by an inability to quantitatively describe multiple modifications on a single protein.

Specificity is the ability of an enzyme to acetylate a discrete residue on $\mathrm{H} 3$, while selectivity is the efficiency of the enzyme to acetylate one position relative to another. In order to quantitate specificity and selectivity of specific lysines on a single protein, we need a method for monitoring acetylation on each lysine residue as a function of time. Site-specific antibody detection requires one antibody for each location and suffers from limitations such as epitope occlusion, which hinders the accuracy of quantitative measurements. This makes it almost impossible to have full coverage of multiple residual modifications via antibody assays. Alternately, radioactive or fluorescence labeling can only measure total acetylation. To overcome these limitations, we developed a label-free quantitative high throughput mass spectrometry method that quantitates the amount of all known sites of acetylation in a single run. Here we demonstrate the use of this assay to characterize the kinetic differences in specificity and selectivity between Gcn5-mediated and nonenzymatic lysine acetylation. Based on the observed catalytic efficiency, we have developed an enzyme specificity and selectivity model describing Gcn5 lysine acetylation.

The experimental and theoretical framework described in this paper not only allows for a more detailed understanding of Gcn5 but also provides a methodology for studying how other KATs acetylate multiple positions on histone H3 and other more complex histone complexes. By developing a robust and expandable assay for measuring histone acetylation we can provide the kinetic parameters not only on primary sites of acetylation but also on the secondary sites shown to be critical in vivo but not previously characterized by traditional assays. Our data suggest that Gen 5 is capable of efficiently acetylating positions K9, K18, and K23 in addition to H3K14. However, these positions are less catalytically efficient than K14, which makes them more susceptible to 
variations in acetyl-CoA levels, which can result from external factors such as a result of changes in metabolism [18].

\section{Materials and Methods}

\section{Reagents}

All Chemicals were purchased from Sigma-Aldrich (St. Louis, MO) or Fisher (Pittsburgh, PA), and the purity is the highest commercial grade or meets LC/MS grade. Ultrapure water was generated from a Millipore Direct-Q 5 ultrapure water system (Bedford, MA). Recombinant histones H3 and H3K14ac were purified and provided from the Protein Purification Core at Colorado State University (http://planetprotein.colostate.edu; for details see $[19,20])$. Human recombinant Gcn5 enzyme was purchased from BPS Bioscience, lot \# 110329 and 111031 (San Diego, CA). Acetyl-CoA was obtained from Sigma-Aldrich. Synthetic peptides (acetylated and propionylated) of high purity $(>98 \%)$ were purchased from JPT peptide technologies (Acton, MA).

\section{Chemical quench}

This assay demands an efficient quenching reagent to prevent the overestimation of acetylation rates. Although denaturants are capable of quenching the reaction, excess salts and acetyl-CoA have to be removed for MS analysis. Thus, an ideal reagent would be compatible with protein precipitation. Three different reagents (trichloroacetic acid (TCA) [21], isopropanol, and acetone [22]) were tested for the quenching efficiency. In order to determine the best quenching reagent, we mixed $180 \mathrm{nM}$ Gcn5 and $200 \mu \mathrm{M}$ acetyl-CoA (identical buffer conditions) with $0.8 \mu \mathrm{M} \mathrm{H} 3$ in $1 / 3$ volumes of TCA (on ice), 2 volumes of isopropanol (on ice), or 4 volumes of acetone $\left(-20^{\circ} \mathrm{C}\right)$ and incubated them overnight at $4{ }^{\circ} \mathrm{C}$. Both isopropanol and acetone resulted in an extra $2-9 \%$ acetylation. TCA was the only quench that resulted in no observable acetylation (data not shown).

\section{Enzymatic kinetics assays for Gen5}

Steady-state and single turnover kinetics for H3 and H3K14ac were performed under identical buffer conditions $(100 \mathrm{mM}$ HEPES buffer (pH 6.8) and $0.08 \%$ Triton X-100) at $37^{\circ} \mathrm{C}$. Histone $\mathrm{H} 3$ concentrations were determined by the measurements of $\mathrm{OD}_{276}\left(\varepsilon_{276}=4040\right)$. Steady-state $(\mathrm{E}<<\mathrm{S})$ assays contained 0.02 to $0.18 \mu \mathrm{M}$ Gcn5, $0.15-45 \mu \mathrm{M} \mathrm{H} 3$ or H3K14ac, and $0.1-$ $200 \mu \mathrm{M}$ acetyl-CoA. Single turnover $(\mathrm{E}>>\mathrm{S})$ assays contained saturating $3 \mu \mathrm{M}$ Gcn5, $0.5 \mu \mathrm{M} \mathrm{H} 3$ and $200 \mu \mathrm{M}$ acetyl-CoA. At varying time points, assays were quenched/precipitated with $25 \%$ $4^{\circ} \mathrm{C}$ TCA, and the precipitate was then washed twice with $150 \mu \mathrm{L}$ acetone $\left(-20^{\circ} \mathrm{C}\right)[23]$. Samples were dried, $1.5 \mu \mathrm{L}$ propionic anhydride was added, and ammonium hydroxide was used to quickly adjust the $\mathrm{pH}$ to $\sim 8$ [24]. Samples were then incubated at $51^{\circ} \mathrm{C}$ for $1 \mathrm{~h}$ followed by trypsin digestion (overnight at $37^{\circ} \mathrm{C}$ ). In addition, nonenzymatic experiments [25] were conducted under the aforementioned assay procedures in the presence and absence of Gcn5, with $12 \mu \mathrm{M}$ histone $\mathrm{H} 3$ and $100-300 \mu \mathrm{M}$ acetyl-CoA.

\section{UPLC-MS/MS analysis}

A Waters Acquity H-class UPLC (Milford, MA) coupled to a Thermo TSQ Quantum Access (Waltham, MA) triple quadrupole (QqQ) mass spectrometer was used to quantify acetylated H3 peptides. The digested $\mathrm{H} 3$ peptides were injected to an Acquity BEH C18 column $(2.1 \times 50 \mathrm{~mm}$; particle size $1.7 \mu \mathrm{m})$ with $0.2 \%$ formic acid (FA) aqueous solution (solution $\mathrm{A}$ ) and $0.2 \% \mathrm{FA}$ in acetonitrile (solution B). Peptides were eluted over $11 \mathrm{~min}$ at $0.6 \mathrm{~mL} / \mathrm{min}$ and $60^{\circ} \mathrm{C}$, and the gradient was programmed from
95\% solution A and 5\% solution B and down to $80 \%$ solution A and $20 \%$ solution B in $11 \mathrm{~min}$. The mass spectrometric conditions were: electrospray voltage: $+4 \mathrm{kV}$; sheath gas pressure: $45 \mathrm{psi}$; auxiliary gas pressure: 20 psi; ion sweep gas pressure: 2 psi; collision gas pressure: $1.5 \mathrm{mTorr}$; andcapillary temperature: $380^{\circ} \mathrm{C}$.Selected reaction monitoring (SRM) was used to monitor the elution of the acetylated and propionylated $\mathrm{H} 3$ peptides. The detail transitions are shown in Table 1.

\section{QqQ MS data analysis}

Each acetylated and/or propionylated peak was identified by retention time and specific transitions (Table 1). The resulting peak integration was done using Xcalibur software (version 2.1, Thermo). The fraction of a specific peptide $\left(\mathrm{F}_{\mathrm{p}}\right)$ is calculated by eq. 1 , where $I_{s}$ is the intensity of a specific peptide state and $I_{p}$ is the intensity of any state of that peptide [26,27]. For

$$
F_{P}=I_{S} /\left(\sum I_{P}\right)
$$

example, the fraction of $\mathrm{K}_{\mathrm{a}} \mathrm{STGGK}_{\mathrm{a}} \mathrm{APR}$ (K9 to R17) can be calculated by the intensity (integrated area) of $\mathrm{K}_{\mathrm{a}} \mathrm{STGGK}_{\mathrm{a}} \mathrm{APR}$ divided by the summed intensities of $\mathrm{K}_{\mathrm{a}} \mathrm{STGGK}_{\mathrm{a}} \mathrm{APR}$, $\mathrm{K}_{\mathrm{p}} \mathrm{STGGK}_{\mathrm{a}} \mathrm{APR}, \mathrm{K}_{\mathrm{a}} \mathrm{STGGK}_{\mathrm{p}} \mathrm{APR}$, and $\mathrm{K}_{\mathrm{p}} \mathrm{STGGK}_{\mathrm{p}} \mathrm{APR}$ which are all possible states of this peptide (subscript a and $\mathrm{p}$ are acetylation and propionylation, respectively). The fraction for a specific residue acetylated can be calculated as the sum of all $\mathrm{F}_{\mathrm{p}}$ that contain that acetylated residue. For example the acetylation of K14 can be obtained by summation of the fractions of $\mathrm{K}_{\mathrm{a}} \mathrm{STGGK}_{\mathrm{a}} \mathrm{APR}$ and $\mathrm{K}_{\mathrm{p}} \mathrm{STGGK}_{\mathrm{a}} \mathrm{APR}$. In order to calculate the fraction of acetylation for two or more positions (e.g. total fraction acetylation), the individual acetylation fractions are added up and divided by the number of lysines. To determine the total amount of acetylation, the sum of the fractions were multiplied by the initial concentration of $\mathrm{H} 3$.

\section{Data analysis}

All models were fit to the data with Prism version 5.0d. The initial rates $(v)$ of acetylation were calculated from the linear increase in acetylation as a function of time prior to a total of $10 \%$ of the sum of all residues being acetylated. To measure steady-state parameters for acetyl-CoA, the initial rates were calculated based on time where less than $10 \%$ of the acetyl-CoA was consumed (based on a coupled assay [28])and where the acetylated H3 fraction mediated by Gen5 is less than 0.1 times the fraction of unacetylated H3. For K14 acetylation, the steady-state parameters $\mathrm{k}_{\text {cat(app) }}, \mathrm{K}_{(\text {app })}$ (i.e. $\mathrm{K}_{\mathrm{m}(\mathrm{app})}$ or $\mathrm{K}_{1 / 2}$ ), and Hill coefficient $(\mathrm{nH})$ were determined by fitting eq. 2, where [S] is the concentration of substrate $(\mathrm{H} 3$ or acetyl-CoA), and [E] is the concentration of Gcn5. The Hill coefficient (nH) was only

$$
\frac{v}{[E]}=k_{\text {cat }(a p p .)} \frac{[S]^{n_{H}}}{\left([S]^{n^{n} H}+K_{(a p p .)}^{n_{H}}\right)}
$$

used when needed (titrating H3K14ac). Modeling acetylation beyond that of H3K14ac was done from scheme 1 (Fig. 1). Our data from equation two suggest that while the titration of acetylCoA will not require a Hill coefficient, the titration of $\mathrm{H} 3 \mathrm{~K} 14 \mathrm{ac}$ has a Hill coefficient of approximately the same value for all three constant. Derivations of scheme 1 (Fig. 1) result in eq. 3, where $v x$ is equal to initial velocity of the location of interest, $\mathrm{A}$ is equal to the multiplication of the three $\mathrm{Ks}$ divided by the $\mathrm{K}$ of interest (eq. 4), 
Table 1. Detection parameters of tryptic peptides from Histone H3.

\begin{tabular}{|c|c|c|c|c|}
\hline & Precursor ion $(\mathrm{m} / \mathrm{z})$ & Product ions (m/z) & Collision energy (eV) & Retention time (min) \\
\hline $\mathrm{TK}_{\mathrm{a}} \mathrm{QTAR}$ & 373.711 & $475.262,645.367$ & 16 & 0.30 \\
\hline TK $_{p} Q T A R$ & 380.706 & $475.262,659.387$ & 16 & 0.41 \\
\hline $\mathrm{K}_{\mathrm{a}} \mathrm{STGGK}_{\mathrm{a}} \mathrm{APR}$ & 493.275 & $570.335,728.404,815.437$ & 20 & 0.44 \\
\hline $\mathrm{K}_{\mathrm{a}} \mathrm{STGGK}_{\mathrm{p}} \mathrm{APR}$ & 500.270 & $584.355,742.424,829.456$ & 20 & 0.65 \\
\hline $\mathrm{K}_{\mathrm{p}} \mathrm{STGGK}_{\mathrm{a}} \mathrm{APR}$ & 500.272 & $570.335,728.404,815.437$ & 20 & 0.69 \\
\hline $\mathrm{K}_{\mathrm{p}} \mathrm{STGGK}_{\mathrm{p}} \mathrm{APR}$ & 507.264 & $584.355,742.424,829.456$ & 21 & 1.14 \\
\hline $\mathrm{K}_{\mathrm{a}} \mathrm{QLATK}_{\mathrm{a}} \mathrm{AAR}$ & 535.819 & $659.383,772.467$ & 22 & 2.99 \\
\hline $\mathrm{K}_{\mathrm{a}} \mathrm{QLATK}_{\mathrm{p}} \mathrm{AAR}$ & 542.814 & $673.402,786.486$ & 22 & 3.99 \\
\hline $\mathrm{K}_{\mathrm{p}} \mathrm{QLATK}_{\mathrm{a}} \mathrm{AAR}$ & 542.816 & $659.383,772.467$ & 22 & 4.11 \\
\hline $\mathrm{K}_{\mathrm{a}} \mathrm{QLATK}_{\mathrm{p}} \mathrm{AAR}$ & 549.809 & $673.402,786.486$ & 22 & 4.95 \\
\hline $\mathrm{K}_{\mathrm{a}}$ SAPATGGVK ${ }_{\mathrm{a}} \mathrm{K}_{\mathrm{a}}$ PHR & 520.627 & $579.336,905.531,1231.690$ & 26 & 4.00 \\
\hline $\mathrm{K}_{\mathrm{p}}$ SAPATGGVK $\mathrm{K}_{\mathrm{a}} \mathrm{PHR}$ & 525.290 & $579.336,905.531,1231.690$ & 26 & 4.60 \\
\hline $\mathrm{K}_{\mathrm{a}}$ SAPATGGVK $\mathrm{K}_{\mathrm{a}} \mathrm{K}_{\mathrm{p}} \mathrm{PHR}$ & 525.292 & $593.355,919.550,1245.709$ & 26 & 4.60 \\
\hline $\mathrm{K}_{\mathrm{a}} \mathrm{SAPATGGVK} \mathrm{K}_{\mathrm{p}} \mathrm{K}_{\mathrm{a}} \mathrm{PHR}$ & 525.294 & $579.336,919.550,1245.709$ & 26 & 4.60 \\
\hline $\mathrm{K}_{\mathrm{p}}$ SAPATGGVK $\mathrm{K}_{\mathrm{a}} \mathrm{PHR}$ & 529.953 & $579.336,919.550,1245.709$ & 27 & 5.10 \\
\hline $\mathrm{K}_{\mathrm{p}} \mathrm{SAPATGGVK}_{\mathrm{a}} \mathrm{K}_{\mathrm{p}} \mathrm{PHR}$ & 529.955 & $593.355,919.550,1245.709$ & 27 & 5.18 \\
\hline $\mathrm{K}_{\mathrm{a}}$ SAPATGGVK $\mathrm{K}_{\mathrm{p}} \mathrm{PHR}$ & 529.957 & $593.355,933.570,1259.729$ & 27 & 5.00 \\
\hline $\mathrm{K}_{\mathrm{p}} \mathrm{SAPATGGVK_{p }} \mathrm{K}_{\mathrm{p}} \mathrm{PHR}$ & 534.616 & $593.355,933.570,1259.729$ & 27 & 5.60 \\
\hline YQK $_{\mathrm{a}}$ STELLIR & 646.864 & $744.461,831.493,1001.598$ & 25 & 8.31 \\
\hline YQK $_{p}$ STELLIR & 653.859 & $744.461,831.493,1015.588$ & 26 & 9.23 \\
\hline $\mathrm{K}_{\mathrm{a}} \mathrm{LPFQR}$ & 415.748 & $450.245,547.298$ & 17 & 5.64 \\
\hline $\mathrm{K}_{\mathrm{p}} \mathrm{LPFQR}$ & 422.742 & $450.245,547.298$ & 18 & 6.35 \\
\hline EIAQDFK $_{\mathrm{a}}$ TDLR & 689.354 & $288.203,936.478$ & 27 & 8.56 \\
\hline $\mathrm{EIAQDFK}_{\mathrm{p}}$ TDLR & 696.349 & $288.203,950.497$ & 27 & 9.31 \\
\hline VTIMPK ${ }_{a}$ DIQLAR & 476.274 & $600.382,715.409,885.515,982.567$ & 24 & 11.13 \\
\hline VTIMPK ${ }_{p}$ DIQLAR & 480.938 & $600.382,715.409,899.534,996.587$ & 24 & 11.69 \\
\hline
\end{tabular}

doi:10.1371/journal.pone.0054896.t001

$$
\frac{v_{x}}{[E]}=k_{x} \frac{A[S]}{\left(K_{9} K_{18} K_{23}\right)+D[S]}
$$$$
A=\frac{K_{9} K_{18} K_{23}}{K_{x}}
$$

$$
D=K_{9} K_{18}+K_{9} K_{23}+K_{18} K_{23}
$$

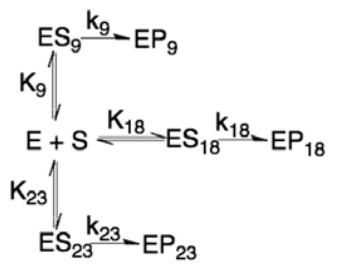

Figure 1. Scheme 1, three competing sites on one substrate (H3).

doi:10.1371/journal.pone.0054896.g001 and $\mathrm{D}$ is equal to eq. 5 . In this mechanism $\left(\mathrm{k}_{\mathrm{cat}} / \mathrm{K}_{1 / 2}{ }^{\mathrm{nH}}\right)_{(\mathrm{app})}$ from eq. 2 becomes eq. 6 , where $\mathrm{k}_{\mathrm{x}}$ is the rate of product formation for the residue of interest and $\mathrm{K}_{\mathrm{x}}$ is equal to the $\mathrm{K}$ of interest.

$$
\left(\frac{k_{\text {cat }}}{K_{m}}\right)_{(\text {app. })}=\frac{k_{x} A / D}{K_{9} K_{18} K_{23} / D}=\frac{k_{x}}{K_{x}}
$$

The catalytic proficiency for specific lysine residue was calculated using eq. 7, where $\mathrm{R}$ is the gas.

$$
\Delta \Delta G_{(a p p)}=-R T \ln \left(\frac{\left(k_{c a t} / K_{m}\right)_{a p p .}}{k_{n E}}\right)
$$

constant, $\mathrm{T}$ is the absolute temperature, $\left(\mathrm{k}_{\mathrm{cat}} / \mathrm{K}\right)_{(\mathrm{app})}$ is catalytic efficiency for the residue of interest, and $\mathrm{k}_{\mathrm{nE}}$ is the second order rate constant for nonenzymatic acetylation. When acetyl-CoA is in an excess amount, nonenzymatic acetylation was described by a single exponential eq. 8,

$$
[P]_{t}=[P]_{\infty}\left(1-e^{-k_{o b s} t}\right)
$$


8where $[\mathrm{P}]_{\mathrm{t}}$ is the concentration of specific acetylated lysine at time $(\mathrm{t})$, which was determined by multiplying the known concentration of initial substrate and the fraction of specifically acetylated lysine, $\mathrm{t}$ is time, and $\mathrm{k}_{\mathrm{obs}}$ is the observed rate. The second order rate constant for nonenzymatic acetylation was determined by eq. 9, where $\mathrm{k}_{\mathrm{obs}}$ is the pseudo-first order rate of acetylation from eq. 8, $[\mathrm{acCoA}]$ is the concentration of acetyl$\mathrm{CoA}, \mathrm{k}_{\mathrm{nE}}$ is the second order rate constant, and $\mathrm{b}$ is the $\mathrm{y}$ intercept.

$$
k_{o b s}=k_{n E}[a c \operatorname{CoA}]+b
$$

\section{Results}

\section{Validation of quantitative analysis of $\mathrm{H} 3$ acetylation (label-free quantitative assay)}

Before we can begin to understand the kinetics of acetylating multiple positions on a single histone, we need to validate our assay. This assay relies on three basic steps: a quench to stop the reaction (See experimental procedures), digestion to obtain fragments optimal for MS, and UPLC-MS/MS. All three of these steps need to be optimized, but quantitative MS analysis is critical for optimization.

Histone digestion. There are two considerations for the tryptic digestion of histones: first, the large numbers of lysines and arginines can result in peptides too small to accurately detect. Second, once lysines are acetylated, they are no longer amiable for digestion. This leaves two options for digestion; chemically alter the lysines or use Arg-C, both of which results in only digesting at arginine residues. Both of these methods have been used with success for studying histone modifications [29,30]. However, Arg$\mathrm{C}$ requires the use of both calcium and surfactants to approach the efficiency of trypsin. Therefore, we chose to propionylate the histone prior to the addition of trypsin. This protocol has been successfully applied to identify and quantify histone PTMs for different research subjects [31-33]. Both chemical propionylation and/or acetylation as a result of the assay will prevent cleavage by trypsin, resulting in the same proteolytic peptides as the Arg-C digestion (Fig. 2). Thus, either unacetylated or acetylated lysines will remain on individual peptides. This avoids loss of detection for very short peptides generated by trypsin alone and neutralizes the charge and increases the hydrophobicity at the unacetylated lysine residuals, providing greater separation on the $\mathrm{C}-18$ column. Thus propionylation reduces the number of experimental steps and contributes to higher reproducibility and simplification of the data processing.

Selected reaction monitoring (SRM) and quantitation. QqQ MS provides unmatched sensitivity, dynamic range, and quantitative capability. SRM allows us to measure specific parent ion to product ion transitions that are both unique to the peptide of interest and to the site of modification (Table 1). We used a series of synthetic peptides in direct infusion experiments for the optimization of collision parameters and to determine which transitions provide the highest intensity for the acetylated and propionylated lysines of interest. The use of synthetic peptides also demonstrates that different acetylation or propionylation patterns within one peptide fragment have the same ionization efficiency. Mixing different ratios of acetylated to propionylated (non-acetylated) peptides followed by QqQ MS, we were able to plot the measured fraction of observed acetylation verses the actual acetylation ratio and observed a slope of 0.99 and an $\mathrm{R} 2=0.998$ (data not shown). This validates both our assumption and others who have used this approach to quantitate histone modifications [31-33]. This allows us to determine the fraction of modification and to confirm that we can indeed measure the low levels of acetylation needed for enzyme kinetics.

\section{Residue specific activity of Gcn5}

The majority of residues acetylated by Gen 5 are located on the tail of histone H3 (e.g. K9, K14, K18, and K23) (Fig. 2), and even small peptide substrates commonly used in kinetic assay have multiple possible locations of acetylation. Therefore, an ideal assay should quantitate all known locations of acetylation. Herein we present a workflow that solves these problems and allows for the study of residue-specific enzyme kinetics.

In order to determine the likely preference of acetylation, we first measured acetylation at several time points up to 2 hours (Fig. 3A). These data confirmed earlier studies [17,34] that K14, $\mathrm{K} 9$, and K23 were the primary acetylation sites at 1 hour. Overnight we also observed acetylation of K18, K27, and K36, but no observable acetylation of K4, K37, K56, K64, K79, and $\mathrm{K} 122$ was found. From these data we focused our kinetic studies to K9, K14, K18, K23, K27, and K36, although all SRMs for other lysines were collected.

\section{Nonenzymatic acetylation}

In order to determine Gcn5-mediated acetylation, we also characterized the specificity of nonenzymatic acetylation. Note that in the nonenzymatic assay, there is no significant lysine acetylation detected at $0.5 \mathrm{~h}$. However, at long time points ( $>6$ hours) in the presence of high levels of acetyl-CoA $(200 \mu \mathrm{M})$, we observed multiple locations of acetylation (Fig. 3B). Interestingly, the sites of acetylation were not random but had a degree of specificity that differed from that of Gen5. The primary site of nonenzymatic acetylation is $\mathrm{K} 36$, followed by K37, both of which are closer to the core of H3. K64 is the third most nonenzymatically acetylated residue; is in the core of $\mathrm{H} 3$ and is not significantly acetylated by Gcn5. We observed no significant acetylation at locations $\mathrm{K} 4, \mathrm{~K} 79$, and $\mathrm{K} 122$. The lack of acetylation on $\mathrm{K} 4$ is also a notable observation due to its location at the end of the histone tail. Together these data suggest that at least some level of structure or reduced conformational dynamics enhances nonenzymatic acetylation.

We next measured rates of nonenzymatic acetylation as a function of time at various concentrations of acetyl-CoA (Fig. 4). $\mathrm{K} 36$ is the first position to be acetylated and the only single position that acetylates to a definable endpoint of $58 \pm 5 \%$ of the total amount of histone (Fig. 4A). It is possible that the acetylation of K 37 sterically inhibits the acetylation of K 36 or that acetylation of the histone somehow alters the histone conformation, limiting acetylation. The acetylation rate of K36 defines the upper limit of how fast any single residue can be nonenzymatically acetylated $\left(4.1 \pm 0.6 \times 10^{-4} \mu \mathrm{M}^{-1} \mathrm{~h}^{-1}\right)$ (Fig. 4B). Using these data (and eq. 8 and 9) we can calculate the expected amount of nonenzymatic acetylation for a given point in time and a set of reaction conditions. This calculation for K36 at a time of 1 hour under saturating conditions yields only 3-6\%, where Gcn5 acetylates $23 \pm 7 \%$ of $\mathrm{K} 36$ in this time.

Monitoring histone acetylation by peptide and specific residue. Monitoring histone acetylation by SRM provides a unique look at the kinetics of acetylation. There are three ways to visualize these data: we can plot the percentage of acetylation on each peptide, the total amount of acetylation at a specific lysine, and the total percent of acetylation. Monitoring the specific peptides, we can observe the appearance of H3K 14 acetylation 


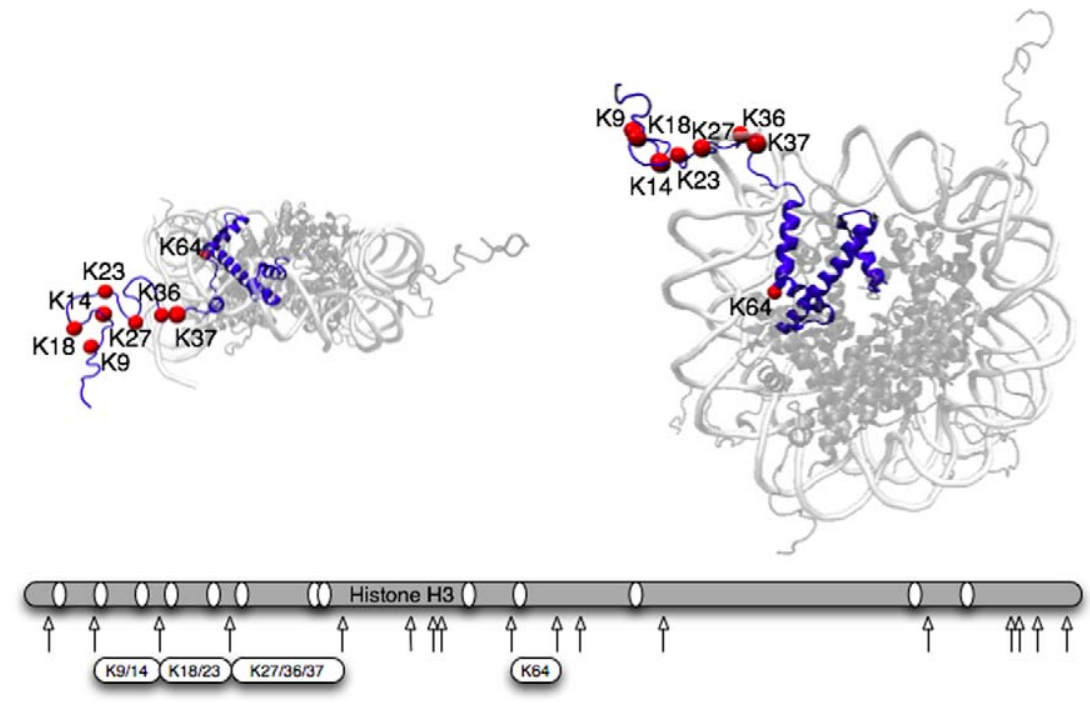

Figure 2. Structure of H3 (blue highlight) in nucleosome, which is constructed from the PDB 1 KX5 nucleosome structure [54]. The red dots show the lysine locations that are reportedly acetylated in this study. The grey bar represents one H3 sequence and the white ovals show the relative lysine sites and arrows are the location of arginines that are the only locations digested by trypsin after chemical propionylation or acetylation.

doi:10.1371/journal.pone.0054896.g002

(KpSTGGKaAPR (K9 to R17)) followed by K9 and K14 both being acetylated (KaSTGGKaAPR). Because we never detected H3K9 acetylation by itself (KaSTGGKpAPR), the combined results demonstrate that $\mathrm{H} 3 \mathrm{~K} 14$ is acetylated prior to $\mathrm{H} 3 \mathrm{~K} 9$ (Fig. 5A). When we expand our analysis to include the other peptides, we also see acetylation of K23 occurring before K18 (Fig. 5B), suggesting the K14 is acetylated first, followed by K9 and $\mathrm{K} 23$, then K18. The rates of K27 and K36 acetylation are slower than K14, K9, and K23, making the determination of the direct
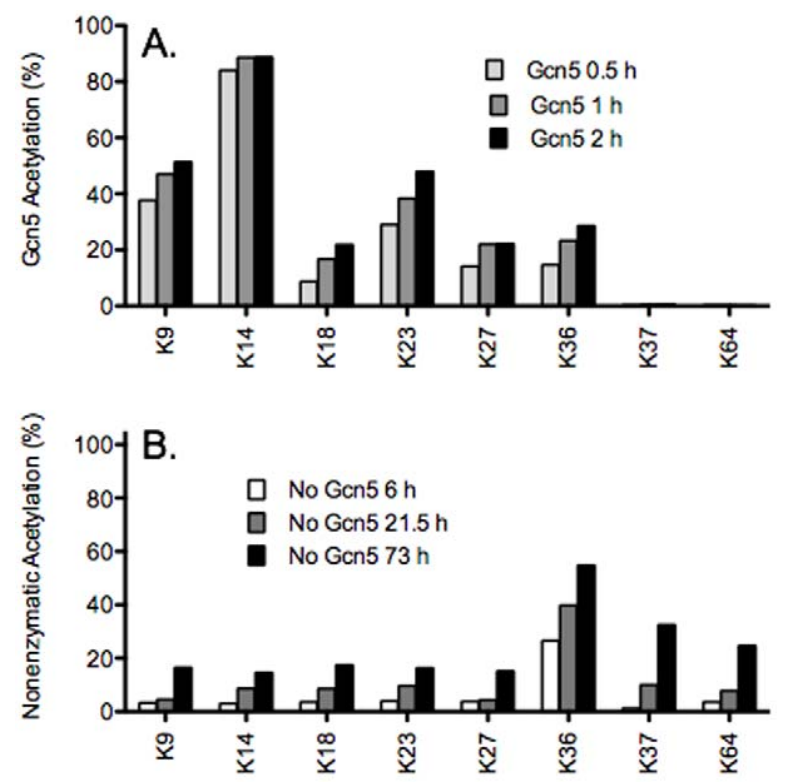

Figure 3. Sites acetylated on histone H3. (A) Gcn5 mediated acetylation of $\mathrm{H} 3(12 \mu \mathrm{M} \mathrm{H3}, 200 \mu$ Macetyl-CoA) at 0.5 (light grey), 1 (dark grey), and 2 (black) hours. (B) Nonenzymatic acetylation of $\mathrm{H} 3$ $(12 \mu \mathrm{M})$ by acetyl-CoA $(200 \mu \mathrm{M})$ at 6 (white), 21.5 (grey), and 73 (black) hours.

doi:10.1371/journal.pone.0054896.g003 order of acetylation difficult. By taking the sum of the fraction of KpSTGGKaAPR (K9 to R17) and KaSTGGKaAPR, we can monitor the total acetylation of K14 (Fig. 5C). To compute the amount of acetylation that would be observed by standard methods, we took the sum of the fraction of every acetylated peptide and multiplied it by the concentration of H3 (Fig. 5D). These data demonstrate how observed rates of total acetylation can be averaged out among those of individual residue acetylation. It is also likely that total acetylation under these conditions could be misinterpreted as biphasic or burst kinetics. This fact highlights the importance of this type of approach when dealing with fulllength histones or substrate with multiple lysines.

Kinetics of initial $\mathbf{H 3}$ acetylation. To ensure that the experiments were under steady-state conditions, we limited our analysis to time points where the sum of the total fraction of acetylated histone was less than $10 \%$. Under these conditions we did not observe any nonenzymatic acetylation, consistent with the estimate derived from the measured second order rate constant. We carried out a series of time course experiments under steadystate conditions, obtained the rate of initial $10 \%$ histone acetylation for different substrate concentrations, and then plotted v/E vs. substrate concentrations (Fig. 6). Using H3 as a substrate under these conditions, only K14 was sufficiently acetylated to determine the initial rate before $>10 \%$ of $\mathrm{H} 3$ had at least one acetylation site. Other residues are acetylated prior to $10 \%$ total acetylation but could not be adequately quantitated with this substrate. The $\mathrm{H} 3$ steady-state parameters for K14 acetylation are $\mathrm{Km}(\mathrm{app})=0.5 \pm 0.02 \mu \mathrm{M}$ and $\operatorname{kcat}(\mathrm{app})=12.1 \pm 0.1 \mathrm{~min}-1$ (Fig. 6A and Table 2 and 3).

In order to monitor the initial rate of acetylation as a function of acetyl-CoA concentration, we had to ensure the assays were under steady-state conditions. This is due to the fact that while we are monitoring the amount of $\mathrm{H} 3$ acetylated we are varying the amount of acetyl-CoA. In other words, when [H3] > [acetyl-CoA] we can only monitor the amount of acetylated $\mathrm{H} 3$ over time up to a concentration $<10 \%$ [acetyl-CoA], but when [H3] $<$ [acetyl$\mathrm{CoA}]$ we can measure up to $<10 \%$ [H3]. Under these conditions, the acetyl-CoA steady-state parameters for K14 acetylation are 
A.

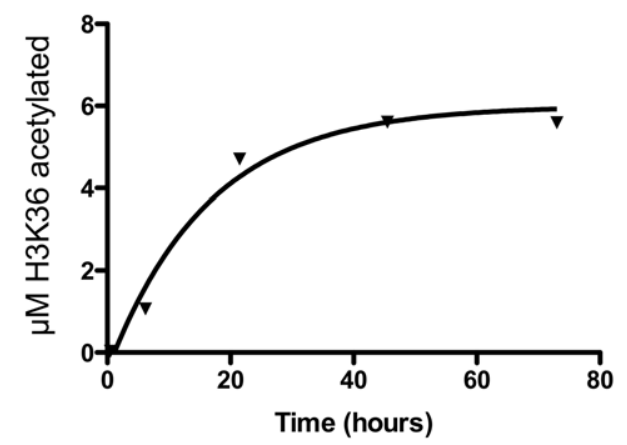

B.

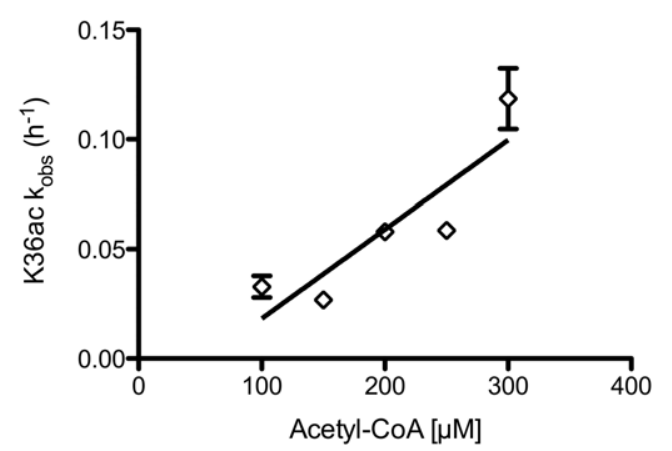

Figure 4. Second order rate constant for nonenzymatic acetylation. (A) Concentrations of acetylated H3K36 as a function of time fit to a pseudo-first order reaction ([acetyl-CoA] $=200 \mu \mathrm{M}$ ) with an apparent rate of $5.8 \pm 0.3 \times 10^{-2} \mathrm{~h}^{-1}$. (B) $\mathrm{k}_{\text {obs }}$ for the nonenzymatic acetylation of K36 as a function of acetyl-CoA concentration resulting in an apparent rate constant of $4.1 \div 0.6 \times 10^{-4} \mu \mathrm{M}^{-1} \mathrm{~h}^{-1}$

doi:10.1371/journal.pone.0054896.g004

$\mathrm{K}_{\mathrm{m}(\mathrm{app})}=0.7 \pm 0.05 \mu \mathrm{M}$ and $\mathrm{k}_{\text {cat(app) }}=11.6 \pm 0.2 \mathrm{~min}^{-1}$ (Fig. $6 \mathrm{~B}$ and Table 2 and 3$)$.

To confirm that K14 is the first site acetylated on H3, we measured the single turnover kinetics under limiting $\mathrm{H} 3$ conditions and excess Gen5 and acetyl-CoA. Under these conditions, H3 exist as H3-Gen5 and $>98 \%$ of K14 is acetylated prior to K9 or
K23 (data not shown). Sequentially, K9 and K23 were the next acetylation sites, which is consistent with our findings from steadystate assays.

H3 acetylation after K14 (H3K14ac as a substrate). To better understand the specificity of Gcn5, we utilized H3K 14 ac as a substrate under steady-state conditions. We hypothesized that
A.

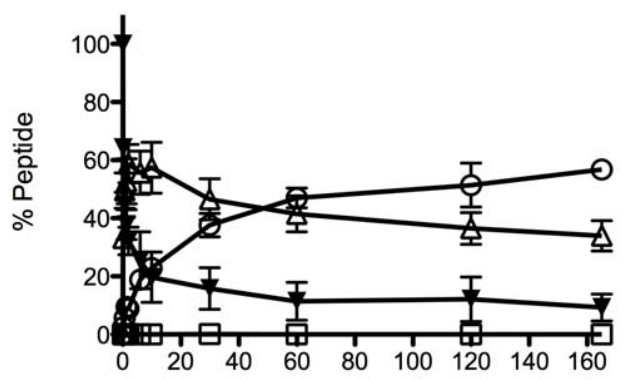

C.

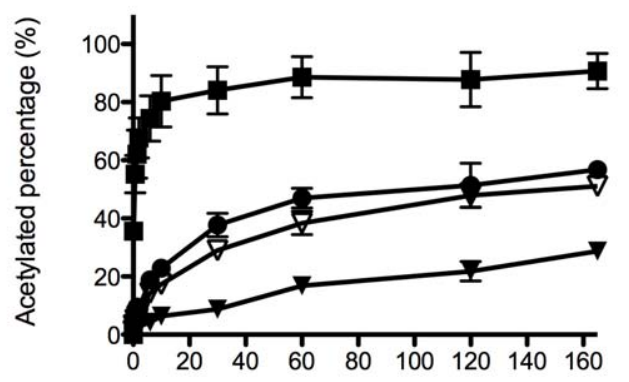

Time (min)
B.

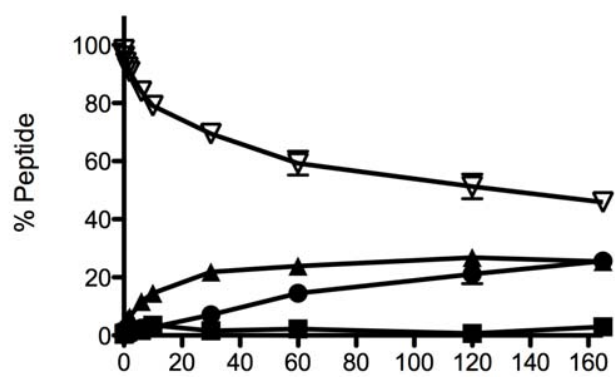

Time (min)

D.

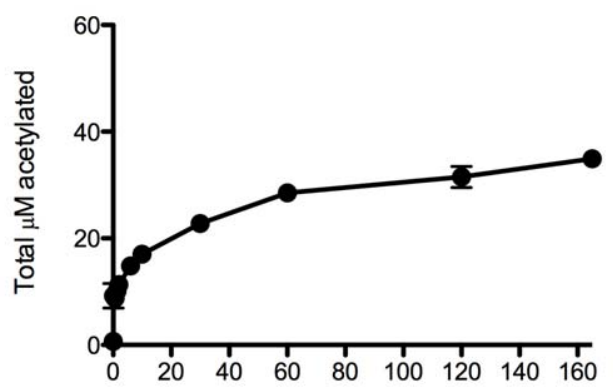

Time (min)

Figure 5. Multiple views of Gcn5-mediated H3 acetylation kinetics from bottom-up MS analysis, when [H3] = 12 $\mu M$, [Gcn5] $=\mathbf{1 8 0} \mathbf{~ n M}$, and [acetyl-CoA] $=\mathbf{2 0 0} \boldsymbol{\mu M}$. (A) Changes of modifications on KSTGGKAPR: $K_{2}$ STGGK $A$ APR (open circle), $K_{2}$ STGGK ${ }_{p} A P R$ (open square), $K_{p} S_{T G G K} A P R$ (open triangle), and $K_{p} S T G G K_{p} A P R$ (solid reverse triangle). (B) Changes of modifications on KQLATKAAR: $K_{a}$ QLATK ${ }_{a} A A R$ (solid circle), $K_{a}{ }_{a}$ LATK $_{p} A A R$ (solid square), $K_{p}$ QLATK $_{a} A A R$ (solid triangle), and $K_{p}$ QLATK ${ }_{p} A A R$ (open reverse triangle). The data of (A) and (B) were directly obtained from MS SRM analysis. (C) Kinetics of fractions of acetylated K9 (solid circle), K14 (solid square), K18 (solid triangle), and K23 (open reverse triangle). (D) Kinetic of total acetylated lysine concentration on H3. The plots of $(C)$ was generated from the calculation of $(A)$ and $(B)$. Apparently, K14 is the primary acetylation lysine by Gcn5 catalysis. While only the total or multiple acetylation is monitored, the acetylation amount from minor acetylation sites could be neglected, especially at short time points.

doi:10.1371/journal.pone.0054896.g005 
A.

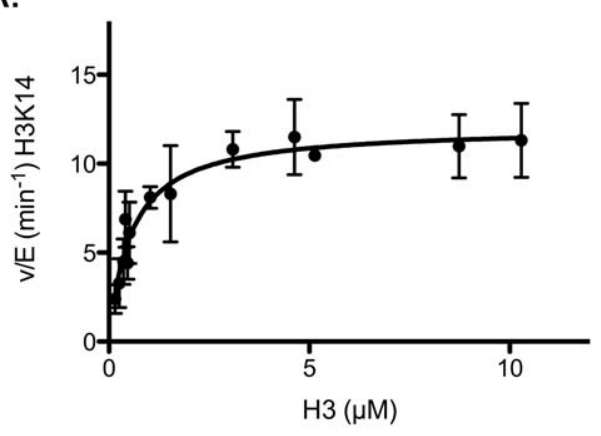

B.

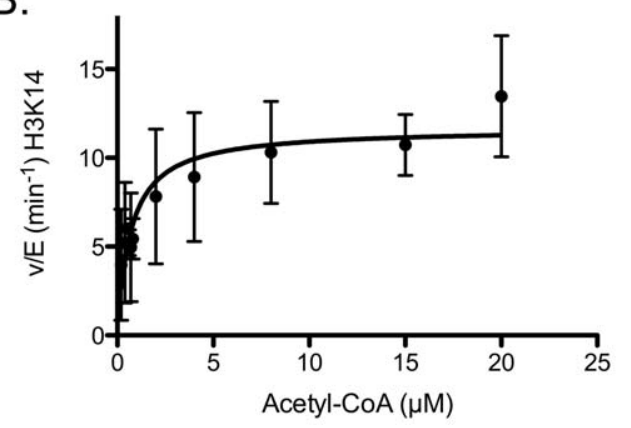

Figure 6. Determination of steady-state kinetic parameters for K14 acetylation by Gcn5. (A) $\mathrm{k}_{\mathrm{cat}}=12.1 \pm 0.1 \mathrm{~min}^{-1}$ and $\mathrm{K}_{\mathrm{m}}$ $=0.5 \pm 0.02 \mu \mathrm{M}$ are determined when [Gcn5] $=18 \mathrm{nM}$, [acetyl-CoA] $=200 \mu \mathrm{M}$ with titrating 13 different $\mathrm{H} 3$ concentrations. (B) $\mathrm{k}_{\mathrm{cat}}$ $=11.6 \pm 0.2 \mathrm{~min}^{-1}$ and $\mathrm{K}_{\mathrm{m}}=0.7 \pm 0.05 \mu \mathrm{M}$ are determined when [Gcn5] $=18 \mathrm{nM},[\mathrm{H} 3]=10 \mu \mathrm{M}$ with titrating different acetyl-CoA concentrations.

doi:10.1371/journal.pone.0054896.g006

while H3K14ac may be critical for transcription, secondary acetylation sites may also play a critical role in biology by improving the binding of bromodomains or competing with methylation (e.g. H3K9) which is critical for gene silencing [35]. This hypothesis is supported by the fact that deletions of gen 5 in vivo result in a loss of acetylation in residues acetylated after K14 $[17,36,37]$. These data suggest that while multiple enzymes (Gcn5, p300/CBP, etc) can acetylate K14 during transcription, Gcn5 may uniquely acetylate chromatin by altering other locations.

To test this hypothesis, we used H3K 14 ac as a starting substrate to determine the kinetic parameters for these second tier acetylation sites (Fig. 7 and Table 2 and 3). Using H3K14ac as a substrate, we observed five additional locations of acetylation: H3K9, K18, K23, K27, and K36. With five possible sites of acetylation, we had to monitor the sum of all acetylation sites to confirm that it was less than $10 \%$ of the total H3 location. Two sites, H3K 9 and H3K23 had the highest level of acetylation, followed by H3K18, H3K27 and H3K36. From these data we calculated the steady-state parameters for H3K9, K18, and K23 (Fig. 7 and Table 2). We were unable to determine parameters for both $\mathrm{K} 27$ and K36, as we could not reach saturation for H3, but we did observe $\mathrm{v} / \mathrm{E}$ rates as high as $2.0 \pm 0.5 \mathrm{~min}^{-1}$, which is faster than we would predict if the modification were simply due to nonenzymatic acetylation. Furthermore, in the time it took for total Gcn 5 meditated acetylation to reach $10 \%$ we were unable to observe any acetylation on any residue in the absence of Gcn5.

The $\mathrm{K}_{\mathrm{m}(\text { app })}$ or $\mathrm{K}_{1 / 2 \text { (app. })}$ for $\mathrm{H} 3 \mathrm{~K} 14$ ac for $\mathrm{K} 9, \mathrm{~K} 18$, and $\mathrm{K} 23$ ranges from 5 to $7 \mu \mathrm{M}$ and has a Hill coefficient of $\sim 2$. It is possible that the Hill coefficient is reflecting the need for $\mathrm{H} 3$ to dimerism for efficient catalysis to occur. The largest difference is between $\mathrm{k}_{\text {cat(app) }}(\mathrm{K} 14 \mathrm{ac}$ substrate) where $\mathrm{K} 9$ and $\mathrm{K} 23$ are between 2-3 $\mathrm{min}^{-1}$ and K18 is approximately $1 \mathrm{~min}^{-1}$ (Table 3). The parameters for acetyl-CoA followed a similar trend but did not require the use of a Hill coefficient. The $\mathrm{K}_{\mathrm{m}(\mathrm{app})}$ for acetyl-CoA for $\mathrm{K} 9$ and $\mathrm{K} 23$ were between $7-12 \mu \mathrm{M}$ but $\mathrm{H} 3 \mathrm{~K} 18$ was $>5$-fold larger $(59 \pm 8 \mu \mathrm{M})$, suggesting it would be the most sensitive to changes in acetyl-CoA levels followed by K9 and K23 (Fig. 7 and Table 2). Single turnover was not informative due to the fact that we could not reach the saturation, consistent with the higher observed $\mathrm{K}_{1 / 2(\mathrm{app})}$. Together these data are consistent with Gcn5 having a much lower efficiency of acetylating these positions relative to $\mathrm{K} 14$.

\section{Quantitating specificity and selectivity of multiple acetylation sites on a single protein}

The specificity of histone acetylation is the ability of a KAT to acetylate a specific lysine. Selectivity is the ability of a KAT to acetylate one lysine relative to another. Specificity for a particular substrate is often defined as its catalytic efficiency or specificity constant $\left(\mathrm{k}_{\mathrm{cat}} / \mathrm{K}_{\mathrm{m}}\right)$ [38]. Selectivity is expressed as the catalytic efficiency of one substrate to another by the ratio $\mathrm{k}_{\text {cat }} / \mathrm{K}_{\mathrm{m}}$ of two substrates [39-41] or as the difference in catalytic proficiency which is the ratio of $\mathrm{k}_{\mathrm{cat}} / \mathrm{K}_{\mathrm{m}}$ to nonenzymatic acetylation rate, $\mathrm{k}_{\mathrm{nE}}$ $[42,43]$. Both $\mathrm{k}_{\mathrm{cat}} / \mathrm{K}_{\mathrm{m}}$ and $\mathrm{k}_{\mathrm{nE}}$ are second order rate constants $\left(\mu \mathrm{M}^{-1} \min ^{-1}\right)$ and thus both catalytic proficiency $\left(\left(\mathrm{k}_{\mathrm{cat}} / \mathrm{K}_{\mathrm{m}}\right) / \mathrm{k}_{\mathrm{nE}}\right)$ and the ratio of two specificity constants $\left(\left(\mathrm{k}_{\mathrm{cat}} / \mathrm{K}_{\mathrm{m}}\right)_{\mathrm{A}} /\left(\mathrm{k}_{\mathrm{cat}} / \mathrm{K}_{\mathrm{m}}\right)_{\mathrm{B}}\right)$ have no units. For this reason we can calculate $\Delta \Delta \mathrm{G}$ for these values. In this instance, both catalytic proficiency $\left(\left(\mathrm{k}_{\mathrm{cat}} / \mathrm{K}_{\mathrm{m}}\right) / \mathrm{k}_{\mathrm{nE}}\right)$ and $\Delta \Delta \mathrm{G}$ relate the ability of Gen5 to acetylate a specific residue relative to the fastest rate any residue can be acetylated nonenzymatically. Selectivity can also be easily obtained simply by taking the difference of $\Delta \Delta \mathrm{Gs}$ of two different residues, and this

Table 2. Steady-state parameters of acetyl-CoA for Gcn5-mediated acetylation (mean \pm standard error) of $\mathrm{H} 3$ (wt) and $\mathrm{H} 3 \mathrm{~K} 14 \mathrm{ac}$.

\begin{tabular}{|c|c|c|c|c|c|c|c|c|}
\hline Substrate & $\begin{array}{l}\text { Residue } \\
\text { Acetylated }\end{array}$ & $\begin{array}{l}\mathbf{K}_{\mathbf{m}(\mathbf{a p p})}\left(\mathbf{K}_{\mathbf{1 /}}\right. \\
2)(\mu \mathbf{M})\end{array}$ & $n_{\mathrm{H}}$ & $\begin{array}{l}\mathbf{k}_{\text {cat(app) }} \\
\left(\min ^{-1}\right)\end{array}$ & $\begin{array}{l}\left(\mathbf{k}_{\text {cat }} / K_{\mathbf{m}}\right)_{(\mathbf{a p p})} \\
\left(\mu \mathbf{M}^{-1} \mathbf{m i n}^{-1}\right)\end{array}$ & $\begin{array}{l}\left(\mathbf{k}_{\text {cat }} / \mathrm{K}_{1 / 2}^{n \mathrm{H}}\right)_{(\text {app })} \\
\left(\mu \mathrm{M}^{-} n^{H} \min ^{-1}\right)\end{array}$ & $\begin{array}{l}\left(\mathbf{k}_{\text {cat }} / K_{\mathrm{m}}\right)_{\text {(app }} / \mathbf{k}_{\mathrm{nE}} \\
(\text { No Units) }\end{array}$ & $\begin{array}{l}\left(\mathbf{k}_{\text {cat }} / K_{m}{ }^{n H}\right)_{(a p p)} / k_{n E} \\
\left(\mu M^{-n H+1}\right)\end{array}$ \\
\hline H3 (wt) & K14 & $0.5 \pm 0.02$ & n.a. & $12.1 \pm 0.1$ & $24.2 \pm 1.0$ & n.a. & $(3.54 \pm \pm 0.48) \times 10^{6}$ & n.a. \\
\hline H3K14ac & K9 & $5.3 \pm 0.2$ & $2.1 \pm 0.6$ & $2.3 \pm 0.07$ & $0.43 \pm 0.02$ & $0.06 \pm 0.02$ & $(6.35 \pm 0.89) \times 10^{4}$ & $(8.58 \pm 1.3) \times 10^{3}$ \\
\hline H3K14ac & K18 & $7.4 \pm 0.4$ & $2.2 \pm 0.7$ & $0.8 \pm 0.03$ & $0.11 \pm 0.01$ & $0.01 \pm 0.003$ & $(1.58 \pm 0.23) \times 10^{4}$ & $(1.43 \pm 0.25) \times 10^{3}$ \\
\hline H3K14ac & K23 & $5.7 \pm 0.4$ & $2.2 \pm 0.9$ & $2.8 \pm 0.1$ & $0.49 \pm 0.04$ & $0.07 \pm 0.03$ & $(7.19 \pm 1.08) \times 10^{4}$ & $(1.06 \pm 0.20) \times 10^{4}$ \\
\hline H3K14ac & K9\&K18\&K23 & $6.5 \pm 0.3$ & $2.3 \pm 0.6$ & $5.7 \pm 0.1$ & $0.88 \pm 0.04$ & $0.08 \pm 0.02$ & $(1.28 \pm 0.18) \times 10^{5}$ & $(1.13 \pm 0.18) \times 10^{4}$ \\
\hline
\end{tabular}

$\Delta \Delta \mathrm{G}_{\text {(app) }}$ was calculated based on the $\left(\mathrm{k}_{\mathrm{cat}} / \mathrm{K}_{\mathrm{m}}\right)_{\text {(app) }} / \mathrm{K}_{\mathrm{nE}}$ where $\mathrm{k}_{\mathrm{nE}}$ is the second order rate constant in $\mu \mathrm{M}^{-1} \mathrm{~min}^{-1}\left(6.83 \pm 0.89 \times 10^{-6}\right)$ for nonenzymatic acetylation $(\mathrm{K} 36)$. doi:10.1371/journal.pone.0054896.t002 
Table 3. Steady-state parameters of H3 (wt) and H3K14ac for Gcn5-mediated acetylation (mean \pm standard error).

\begin{tabular}{|c|c|c|c|c|c|c|c|c|}
\hline Substrate & $\begin{array}{l}\text { Residue } \\
\text { Acetylated }\end{array}$ & $\begin{array}{l}K_{m(a p p)}\left(K_{1 /}\right. \\
2)(\mu M)\end{array}$ & $n_{\mathrm{H}}$ & $\begin{array}{l}\mathbf{k}_{\text {cat(app) }} \\
\left(\min ^{-1}\right)\end{array}$ & $\begin{array}{l}\left(\mathbf{k}_{\text {cat }} / K_{\mathbf{m}_{1}}\right)_{(\mathbf{a p p})} \\
\left(\mu \mathbf{M}^{-1} \mathbf{m i n}^{-1}\right)\end{array}$ & $\begin{array}{l}\left(\mathbf{k}_{\text {cat }} / \mathrm{K}_{1 / 2}{ }^{n \mathrm{H}}\right)_{(\text {app })} \\
\left(\mu \mathrm{M}^{-} n^{H} \min ^{-1}\right)\end{array}$ & $\begin{array}{l}\left(\mathbf{k}_{\text {cat }} / K_{\mathrm{m}}\right)_{\text {(appp) }} / \mathbf{k}_{\mathrm{nE}} \\
\text { (No Units) }\end{array}$ & $\begin{array}{l}\left(\mathbf{k}_{\text {cat }} / \mathbf{K}_{\mathbf{m}}{ }^{n \mathbf{H}}\right)_{(\mathbf{a p p})} / \mathbf{k}_{\mathrm{nE}} \\
\left(\mu \mathbf{M}^{-\mathbf{n}+\mathbf{+}}\right)\end{array}$ \\
\hline $\mathrm{H} 3(w \mathrm{t})$ & K14 & $0.5 \pm 0.02$ & n.a. & $12.1 \pm 0.1$ & $24.2 \pm 1.0$ & n.a. & $(3.54 \pm \pm 0.48) \times 10^{6}$ & n.a. \\
\hline H3K14ac & K9 & $5.3 \pm 0.2$ & $2.1 \pm 0.6$ & $2.3 \pm 0.07$ & $0.43 \pm 0.02$ & $0.06 \pm 0.02$ & $(6.35 \pm 0.89) \times 10^{4}$ & $(8.58 \pm 1.3) \times 10^{3}$ \\
\hline H3K14ac & K18 & $7.4 \pm 0.4$ & $2.2 \pm 0.7$ & $0.8 \pm 0.03$ & $0.11 \pm 0.01$ & $0.01 \pm 0.003$ & $(1.58 \pm 0.23) \times 10^{4}$ & $(1.43 \pm 0.25) \times 10^{3}$ \\
\hline H3K14ac & $\mathrm{K} 23$ & $5.7 \pm 0.4$ & $2.2 \pm 0.9$ & $2.8 \pm 0.1$ & $0.49 \pm 0.04$ & $0.07 \pm 0.03$ & $(7.19 \pm 1.08) \times 10^{4}$ & $(1.06 \pm 0.20) \times 10^{4}$ \\
\hline H3K14ac & K9\&K18\&K23 & $6.5 \pm 0.3$ & $2.3 \pm 0.6$ & $5.7 \pm 0.1$ & $0.88 \pm 0.04$ & $0.08 \pm 0.02$ & $(1.28 \pm 0.18) \times 10^{5}$ & $(1.13 \pm 0.18) \times 10^{4}$ \\
\hline
\end{tabular}

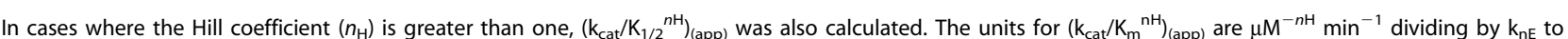
determine $\left(\mathrm{k}_{\mathrm{cat}} / \mathrm{K}_{1 / 2}{ }^{n \mathrm{H}}\right)_{(\mathrm{app})} / \mathrm{k}_{\mathrm{nE}}\left(\mathrm{k}_{\mathrm{nE}}=6.83 \pm 0.89 \times 10^{-6} \mu \mathrm{M}^{-1} \mathrm{~min}^{-1}\right)$ results in $\mu \mathrm{M}$ to the power of the $-n_{\mathrm{H}}+1\left(\mu \mathrm{M}^{-\mathrm{nh}+1-}\right)$. For this reason we can not calculate a $\left.\Delta \Delta \mathrm{G}_{(\mathrm{app})}\right)$ for anything other than $\mathrm{K} 14 \mathrm{ac}\left(n_{\mathrm{H}}=1, \Delta \Delta \mathrm{G}_{(\mathrm{app} .)}=-9.3 \pm 0.08 \mathrm{kcal} \mathrm{mol}^{-1}\right)$.

doi:10.1371/journal.pone.0054896.t003

value equals the $\Delta \Delta \mathrm{G}$ of selectivity calculated by $-\mathrm{RT} \ln \left(\left(\mathrm{k}_{\mathrm{cat}}\right)\right.$ $\left.\left.\mathrm{K}_{\mathrm{m}}\right)_{\mathrm{A}} /\left(\mathrm{k}_{\mathrm{cat}} / \mathrm{K}_{\mathrm{m}}\right)_{\mathrm{B}}\right)$.

We calculated $\mathrm{k}_{\text {cat }} / \mathrm{K}_{\mathrm{m}},\left(\mathrm{k}_{\mathrm{cat}} / \mathrm{K}_{\mathrm{m}}\right) / \mathrm{k}_{\mathrm{nE}}$, and $\Delta \Delta \mathrm{G}$ for residues $\mathrm{K} 9, \mathrm{~K} 14, \mathrm{~K} 18$, and $\mathrm{K} 23$ for acetyl-CoA depend acetylation of $\mathrm{H} 3$ and H3K14ac by Gcn5. Using H3 as a substrate, we demonstrate a 2.4 million-fold $\left((2.43 \pm 0.49) \times 10^{6}\right)$ increase in catalytic efficiency of K14 acetylation as compared to the fastest site of nonezymatic acetylation (K36) (Table 2). While a million-fold enhancement is consistent with other enzymes such as a carbonic anhydrase or chorismate mutase $[43,44]$, the rate of nonenzymatic acetylation of K36 is much faster than the nonenzymatic acetylation of K14 and therefore this rate is an underestimate of enhancement for this site. This does provide good insight into the level of specificity for K14 acetylation achieved by Gcn5. In order to measure the specificity and selectivity of sites other than K14ac we used H3K14ac as a substrate. While we observe acetylation of these sites with $\mathrm{H} 3$ as a substrate, they are too low too quantitate prior to $10 \%$ total acetylation, and single turnover suggests the K14ac is completely acetylated before any other residues. We measured catalytic proficiency for acetyl-CoA from $10^{3}-10^{6}$ or -4.9 to -9.1 $\mathrm{kcal} / \mathrm{mol}$. Together these data suggest over a million-fold increase in specificity and up to a 1000-fold difference in selectivity between $\mathrm{K} 14$ and K18, the lowest measured catalytic proficiency. In addition, this selectivity is two orders of magnitude less than what is achieved by serine proteases [43] consistent with multiple sites being acetylated.

Specificity and selectivity in cooperative systems. We also measure the steady-state parameters for H3 and H3K14ac dependent acetylation by Gcn5. The acetylation of H3 was hyperbolic and displayed similar catalytic proficiency for K14 as acetyl-CoA $(3.54 \pm 0.48 \times 106)$. However, the acetylation of H3K14ac (substrate) was cooperative and as such does not follow the classical Michaelis-Menten equation (Table 3). In this case both the $\mathrm{Km}(\mathrm{app})$ or $\mathrm{K} 1 / 2$ and the Hill coefficient need to be considered to understand specificity. For this $(\mathrm{kcat} / \mathrm{Km})$ is replaced by $(\mathrm{kcat} / \mathrm{K} 1 / 2 \mathrm{nH})$, where $\mathrm{nH}$ is the Hill coefficient [38]. While this analysis can be used to describe specificity and selectivity, it cannot be used to calculate a $\Delta \Delta \mathrm{G}$ because both (kcat/K1/2nH)A/(kcat/K1/2nH)B and $(\mathrm{kcat} / \mathrm{K} 1 / 2 \mathrm{nH}) / \mathrm{knE}$ have units of min- $1 \mu \mathrm{M}-\mathrm{nHA}+\mathrm{nHB}$ or min- $1 \mu \mathrm{M}-\mathrm{nH}+1$ respectively [38]. A Hill coefficient $\sim 2$ makes a $\sim 6$-11-fold difference in catalytic proficiency and efficiency and up to 100-fold in (kcat/ $\mathrm{Km}) \mathrm{K} 14 /(\mathrm{kcat} / \mathrm{Km}) \mathrm{X}$ but makes little to no difference in selectivity between residues $\mathrm{K} 9, \mathrm{~K} 18$, and $\mathrm{K} 23$ due the fact that these residues all display similar Hill coefficients.

\section{Discussion}

The goal of this work was to lay the experimental and theoretical foundation to quantitate the specificity and selectivity of enzymes such as Gcn5, which can modify multiple lysines on a single protein substrate. The ability of an enzyme to modify multiple locations on a single protein suggests the potential of controlling multiple cell signals. This concept is similar to what in electronics would be called a multiplexer or a device that can send multiple signals down a single wire. The difficulty in studying a biological multiplexer is isolating a specific signal or modification. To solve this problem, we have developed an assay capable of monitoring all of the positions that can be acetylated by Gen5, and in doing so we have demonstrated that label-free quantitative high throughput MS is a valuable quantitative method for studying enzyme kinetics. This assay has the advantage of not requiring isotopic reagents, can work with histones in any form from free in solution to nucleosomes, and is not hindered by multiple acetylation sites on a single histone.

Our first step to understanding the specificity of Gcn5 was simply to look at a full time course under steady-state conditions where histone $\mathrm{H} 3$ and acetyl-CoA were saturating. Under these conditions, we observed multiple positions of acetylation, but the highest efficiency was obviously $\mathrm{K} 14$, which is consistent with published results [17]. In addition, under conditions where only $10 \%$ of $\mathrm{H} 3$ is acetylated, $\mathrm{K} 14$ is the only measurable site of acetylation. We did not observe any acetylation of K9 in the absence of K14ac, even when K14 is more than $10 \%$ acetylated. We hypothesize that this is due to a much higher specificity for K14 and/or a dependence on K14ac. Similarly, K18 acetylation was followed by K23 acetylation, although 1-2\% K18 acetylation was detected without K23 acetylation. Together this evidence strongly suggests that Gcn5 does not provide a random acetylation pattern in vitro. With $\mathrm{H} 3$ as a substrate, Gcn5 preferentially acetylates $\mathrm{K} 14>\mathrm{K} 9 \approx \mathrm{K} 23>\mathrm{K} 18>\mathrm{K} 27 \approx \mathrm{K} 36$. These data also demonstrate label-free quantitative MS can be easily applied to steady-state and single turnover approaches.

With multiple sites of acetylation, we needed a reference point for comparison. The most logical reference point is to compare catalytic proficiency or $\left(\mathrm{k}_{\mathrm{cat}} / \mathrm{K}_{\mathrm{m}}\right) / \mathrm{k}_{\mathrm{nE}}$. While we were able to measure the second order rate constant for K36, other sites were difficult due to their low level of acetylation. Given that our goal is to understand the specificity of acetylation, we chose to use the rate of $\mathrm{K} 36$ nonenzymatic acetylation of $\mathrm{H} 3$ to represent the fastest possible rate a residue could be acetylated nonenzymatically. In this way, the catalytic proficiency reflects the ability of the enzyme to acetylate a specific residue relative to nonenzymatic acetylation on $\mathrm{H} 3$. This also allows for easy comparison because 
A.

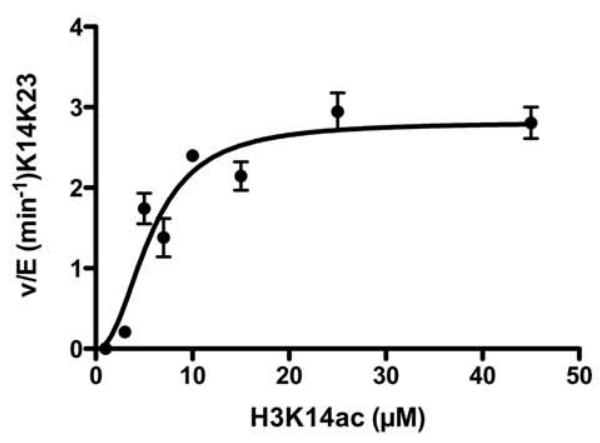

B.

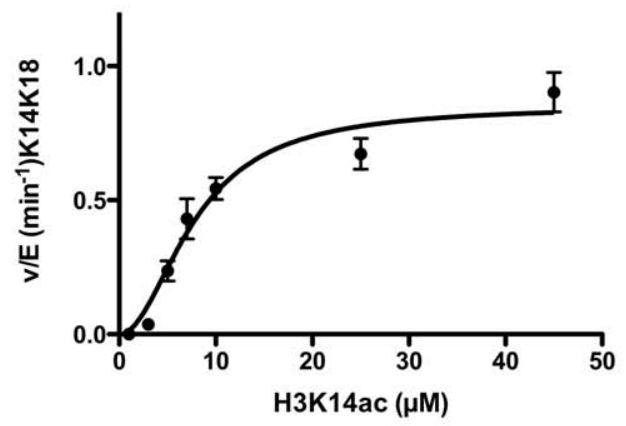

C.

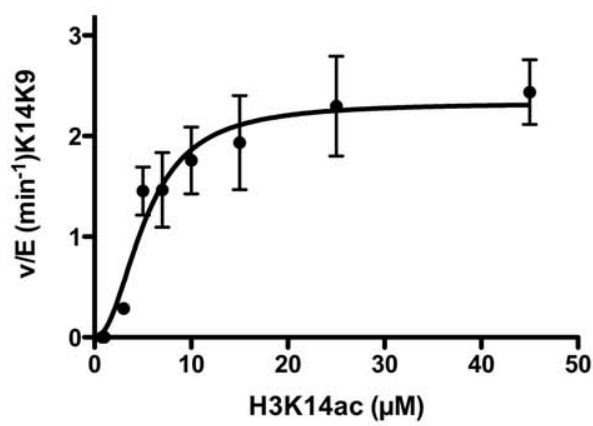

D.

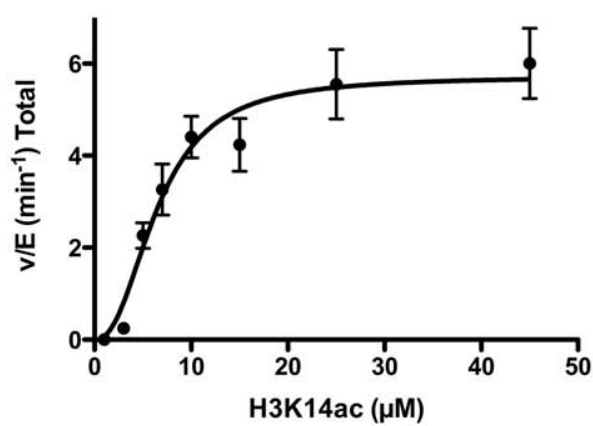

E.

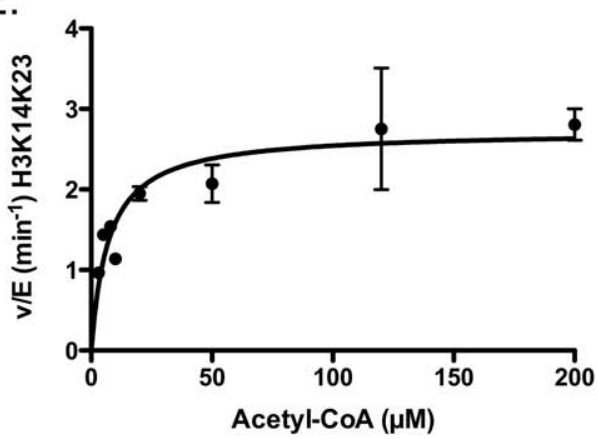

F.

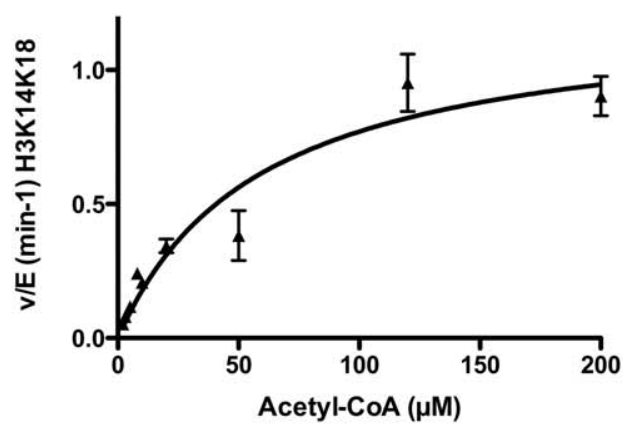

G.

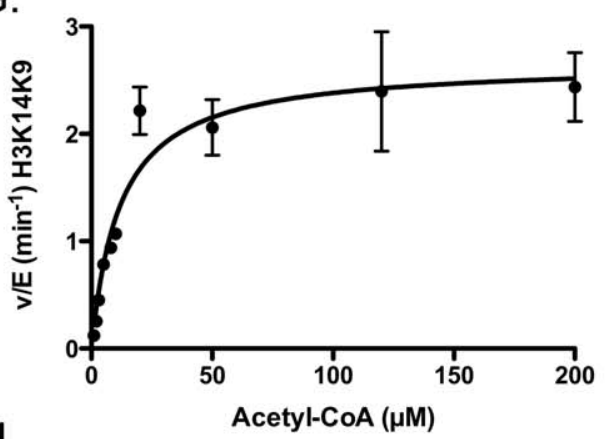

$\mathrm{H}$.

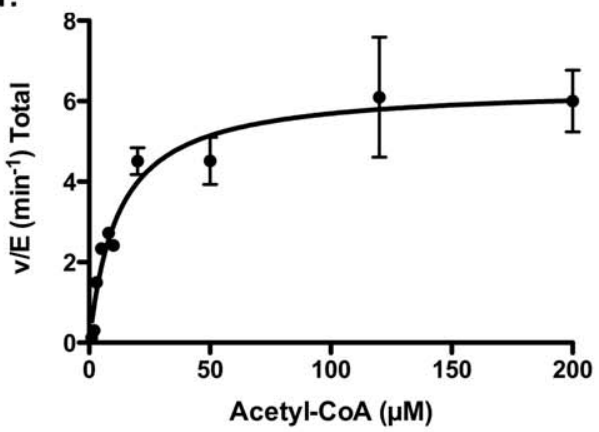

Figure 7. Determination of steady-state kinetic parameters of Gcn5-mediated acetylation of H3K14ac for individual and total lysine residues (i.e. K9, K18, and K23). The left panels (A)-(D) show the data when titrating H3K14ac; and the right panels (E)-(H) show the data when titrating acetyl-CoA. The apparent kinetic parameters are listed in Table 2 . When fitting data from $(A)$ to $(D)$, the Hill coefficient $\left(n_{H}\right)$ is approximately equal to 2, suggesting H3K14ac could form a dimer to be further acetylated. doi:10.1371/journal.pone.0054896.g007

the selectivity is the difference in the ??G (catalytic proficiency) between residues and is the same as the ??G calculated by using ratio of $\mathrm{k}_{\mathrm{cat}} / \mathrm{K}_{\mathrm{m}}$ for two different residues.

We found a surprising degree of specificity to the nonenzymatic acetylation, with K36 being more acetylated than other positions.
Although it is difficult to know if the nonenzymatic modification actually has a significant biological role, it has been found that nonenzymatic methylation plays a role in protein methylation of older human crystalline lens [45]. Given the rate of acetylation for H3K36, the reported half-life of histones in heterochromatin 
ranging from $\sim 100$ to $\sim 600$ days $[46,47]$ and $\mathrm{H} 3$ concentrations of $\sim 0.1 \mathrm{mM}$, nonenzymatic acetylation could be a possibility in vivo. While there is no definitive proof that nonenzymatic acetylation occurs in vivo, it has been suggested in mitochondria where high levels of acetylation are observed in the absence of any known KAT $[48,49]$. In addition to H3 nonenzymatic acetylation has also been demonstrated on other proteins in vitro such as HIV1 Tat, a protein that interacts with p300 [50].

Under the given conditions, we observed that K14 is the primary acetylation site for Gcn5. However, sites acetylated after $\mathrm{K} 14$ are difficult to characterize because when the majority of the substrate is $\mathrm{H} 3 \mathrm{~K} 14 \mathrm{ac}$, there is still a minor portion of unacetylated $\mathrm{H} 3$ and it would be difficult to calculate the time delay between the production of $\mathrm{H} 3 \mathrm{~K} 14 \mathrm{ac}$ and the acetylation of the other sites. To solve this problem, we needed to start with H3K14ac, which can be considered a natural substrate given the higher efficiency of $\mathrm{K} 14 \mathrm{ac}$ production and Gcn5's multiple roles in vivo $[35,51]$. Therefore, starting with H3K $14 \mathrm{ac}$ as a substrate will still provide a biologically relevant mechanism. These data suggest that under saturating conditions of acetyl-CoA and H3K14ac, K9 and K23 can be acetylated with approximately equal efficiency. But the acetylation of any secondary site is more dependent on acetyl-CoA concentration as reflected by the lower catalytic proficiency and efficiency. Consistent with this idea is the fact that the acetyl-CoA induced activation of SAGA (a complex which contains Gcn5) in vivo results in an increase of acetylation at K9, K14, K18, K23, and $\mathrm{K} 27$ of $\mathrm{H} 3$, but that $\mathrm{H} 3 \mathrm{~K} 14$ is the least and $\mathrm{K} 18$ is the most dependent on acetyl-CoA concentration [52]. We observed a change in specificity between saturating $\mathrm{H} 3$ and acetyl-CoA for $\mathrm{H} 3 \mathrm{~K} 18 \mathrm{ac}$ possibly due to the difficulties in measuring extremely low rates of turnover as compared to K9 and K23. While we can observe acetylation on residues $\mathrm{K} 27$ and K36, we do not reach saturation on these positions under testable concentrations of $\mathrm{H} 3$. We hypothesize that the observed change in catalytic efficiency might reflect a way in which the cell can act to block K9 methylation under conditions of high metabolic activity or allow methylation in case of starvation.

The $\mathrm{K}_{\mathrm{m}}$ of H3K14ac is less than that reported by Tanner and colleagues using calf thymus core histones [53] and this is likely due to different experimental conditions. However, a model of multiple competitive acetylation sites on a single substrate might explain this difference (Fig. 1). This model predicts that it would require a greater than 100 -fold difference between either $\mathrm{k}_{\text {cat }}$ or $\mathrm{K}_{\mathrm{m}}$ for $\mathrm{H} 3 \mathrm{~K} 14$ and the other locations before total acetylation would reflect acetylation for H3K14ac. Under our conditions we observe only a difference of 2-15-fold in $\mathrm{k}_{\text {cat }}$ and a 10-15-fold difference in $\mathrm{K}_{\mathrm{m}}$, suggesting that a portion of the measured total acetylation is from $\mathrm{H} 3 \mathrm{~K} 9, \mathrm{H} 3 \mathrm{~K} 18$, and $\mathrm{H} 3 \mathrm{~K} 23$. It is important to

\section{References}

1. Berger SL (2002) Histone modifications in transcriptional regulation. Curr Opin Genet Dev 12: 142-148.

2. Seligson DB, Horvath S, McBrian MA, Mah V, Yu H, et al. (2009) Global levels of histone modifications predict prognosis in different cancers. Am J Pathol 174: $1619-1628$.

3. Hou LF, Wang H, Sartori S, Gawron A, Lissowska J, et al. (2010) Blood leukocyte DNA hypomethylation and gastric cancer risk in a high-risk Polish population. Int J Cancer 127: 1866-1874.

4. Fabris S, Bollati V, Agnelli L, Morabito F, Motta V, et al. (2011) Biological and clinical relevance of quantitative global methylation of repetitive DNA sequences in chronic lymphocytic leukemia. Epigenetics 6: 188-194.

5. Sterner DE and Berger SL (2000) Acetylation of histones and transcriptionrelated factors. Microbiol. Mol Biol Rev 64: 435-459.

6. Lee KK and Workman JL (2007) Histone acetyltransferase complexes: one size doesn't fit all. Nat Rev Mol Cell Biol 8: 284-295.

7. Fraga MF, Ballestar E, Villar-Garea A, Boix-Chornet M, Espada J, et al. (2005) Loss of acetylation at Lys 16 and trimethylation at Lys20 of histone $\mathrm{H} 4$ is a common hallmark of human cancer. Nat Genet 37: 391-400. note that we observe the same ternary complex formation mechanism for H3K14 acetylation (data not shown) consistent with that proposed by Tanner and colleagues [53]. The critical difference between our studies and others is that we are focused on understanding specificity from a residue specific level. In the case of multiple competitive acetylation sites on a single substrate (eq. 3, 4, and 5), each location of acetylation can influence the individual observed $\mathrm{k}_{\text {cat }}$ and $\mathrm{K}_{\mathrm{m}}$ values of other locations of acetylation but $\operatorname{not}\left(\mathrm{k}_{\mathrm{cat}} / \mathrm{K}_{\mathrm{m}}\right)_{\text {(app) }}$ (eq. 6). Therefore, as long as the acetylation of a specific site is being measured and the initial rate is measured prior to $10 \%$ of the total substrate being acetylated at any site, the observed parameters of $\left(\mathrm{k}_{\mathrm{cat}} / \mathrm{K}_{\mathrm{m}}\right)_{(\mathrm{app})}$ are unaffected by other sites of acetylation.

In this paper we have demonstrated the use of a label-free high throughput assay capable of quantitatively monitoring all of the acetylated positions on histone $\mathrm{H} 3$. While this assay is compatible with histones obtained from any source, the throughput makes it an ideal assays for studying enzymes which can modify multiple positions on the same histone. Using this assay we have characterized the selectivity and specificity of both the nonenzymatic and Gen5 (enzymatic) mediated acetylation. In doing so we have shown that catalytic efficiently for both nonenzymatic and enzymatic acetylation is residue dependent. Furthermore, while it is known that altering the intracellular acetyl-CoA levels reduces histone acetylation in cells [18], our data suggest that this change will have a larger effect on secondary sites of acetylation with $\mathrm{K}_{\mathrm{m}(\mathrm{app})}$ increasing as much as 80 -fold. This approach provides a means to begin understanding the mechanism of acetylation and how a few key enzymes modify diverse sites. It is certainly interesting to speculate that the critical differences between KATs are due to their secondary acetylation sites in addition to the primary site, which must be acetylated to initiate transcription. This would imply that the KATs are capable of leaving signals as to which complex activates transcription and/or which gene should be blocked from silencing.

\section{Acknowledgments}

We gratefully thank Dr. Karolin Luger at Colorado State University for the generous gift of purified histone H3 and H3K14. We are grateful to Ryan Henry, Jeremy Day-Storms, James Hougland and Jeff Peterson for their useful discussion and comments.

\section{Author Contributions}

Conceived and designed the experiments: AJA YMK. Performed the experiments: YMK. Analyzed the data: YMK AJA. Contributed reagents/ materials/analysis tools: YMK AJA. Wrote the paper: YMK AJA.

8. Masumoto H, Hawke D, Kobayashi R, and Verreault A (2005) A role for cellcycle-regulated histone $\mathrm{H} 3$ lysine 56 acetylation in the DNA damage response. Nature 436: 294-298.

9. Jenuwein T and Allis CD (2001) Translating the histone code. Science 293: 1074-1080.

10. Oliver SS and Denu JM (2011) Dynamic interplay between histone H3 modifications and protein interpreters: emerging evidence for a "histone language". ChemBioChem 12: 299-307.

11. Schiltz RL, Mizzen CA, Vassilev A, Cook RG, Allis CD, et al. (1999) Overlapping but distinct patterns of histone acetylation by the human coactivators p300 and PCAF within nucleosomal substrates. J Biol Chem 274: 1189-1192.

12. Lau OD, Courtney AD, Vassilev A, Marzilli LA, Cotter RJ, et al. (2000) p300/ CBP-associated factor histone acetyltransferase processing of a peptide substrate. J Biol Chem 275: 21953-21959.

13. Trievel RC, Li FY, Marmorstein R (2000) Application of a fluorescent histone acetyltransferase assay to probe the substrate specificity of the human p300/ CBP-associated factor. Anal Biochem 287: 319-328. 
14. Jiang L, Smith JN, Anderson SL, Ma P, Mizzen CA, et al. (2007) Global assessment of combinatorial post-translational modification of core histones in yeast using contemporary mass spectrometry: LYS4 trimethylation correlates with degree of acetylation on the same H3 tail. J Biol Chem 282: 27923-27934.

15. Berndsen CE and Denu JM (2008) Catalysis and substrate selection by histone/ protein lysine acetyltransferases. Curr Opin Struct Biol 18: 682-689.

16. Li TT, Du YP, Wang LK, Huang L, Li WL, et al. (2012) Characterization and prediction of lysine (K)-acetyl-transferase specific acetylation sites. Mol Cell Proteomics 11.1.

17. Kuo MH, Brownell JE, Sobel RE, Ranalli TA, Cook RG, et al. (1996) Transcription-linked acetylation by Gen5p of histones $\mathrm{H} 3$ and $\mathrm{H} 4$ at specific lysines. Nature 383: 269-272.

18. Wellen KE, Hatzivassiliou G, Sachdeva UM, Bui TV, Cross JR, et al. (2009) ATP-citrate lyase links cellular metabolism to histone acetylation. Science 324: 1076-1080.

19. Neumann H, Peak-Chew SY, Chin JW (2008) Genetically encoding N-epsilonacetyllysine in recombinant proteins. Nat Chem Biol 4: 232-234

20. Andrews AJ, Chen X, Zevin A, Stargell LA, Luger K (2010) The histone chaperone Nap1 promotes nucleosome assembly by eliminating nonnucleosomal histone DNA interactions. Mol Cell 37: 834-842.

21. Rüchel R (1981) Properties of a purified proteinase from the yeast Candida albicans. Biochim Biophys Acta 659: 99-113.

22. Hudgin RL, Pricer WE, Ashwell G, Stockert RJ, Morell AG (1974) Isolation and properties of a rabbit liver binding-protein specific for asialoglycoproteins. J Biol Chem 249: 5536-5543.

23. Kim SC, Chen Y, Mirza S, Xu Y, Lee J, et al. (2006) A clean, more efficient method for in-solution digestion of protein mixtures without detergent or urea. J Proteome Res 5: 3446-3452.

24. Garcia BA, Mollah S, Ueberheide BM, Busby SA, Muratore TL, et al. (2007) Chemical derivatization of histones for facilitated analysis by mass spectrometry. Nature Protocols 2: 933-938.

25. Paik WK, Pearson D, Lee HW, Kim S (1970) Nonenzymatic acetylation of histones with acetyl-CoA. Biochim Biophys Acta 213: 513-522.

26. Liu B, Lin YH, Darwanto A, Song XH, Xu GL, et al. (2009) Identification and Characterization of Propionylation at Histone H3 Lysine 23 in Mammalian Cells. J Biol Chem 284: 32288-32295.

27. Schneider TD, Arteaga-Salas JM, Mentele E, David R, Nicetto D, et al. (2011) Stage-specific histone modification profiles reveal global transitions in the xenopus embryonic epigenome. Plos One 6: e22548.

28. Kim Y, Tanner KG, Denu JM (2000) A continuous, nonradioactive assay for histone acetyltransferases. Anal Biochem 280: 308-314.

29. Zhang LW, Eugeni EE, Parthun MR, Freitas MA (2003) Identification of novel histone post-translational modifications by peptide mass fingerprinting. Chromosoma 112: 77-86.

30. McKittrick E, Gaften PR, Ahmad K, Henikoff S (2004) Histone H3.3 is enriched in covalent modifications associated with active chromatin. Proc Natl Acad Sci U S A 101: 1525-1530.

31. Johnson L, Mollah S, Garcia BA, Muratore TL, Shabanowitz J, et al. (2004) Mass spectrometry analysis of Arabidopsis histone $\mathrm{H} 3$ reveals distinct combinations of post-translational modifications. Nucleic Acids Res 32: 65116518.

32. Garcia BA, Busby SA, Shabanowitz J, Hunt DF, Mishra N (2005) Resetting the epigenetic histone code in the MRL-lpr/lpr mouse model of lupus by histone deacetylase inhibition. J Proteome Res 4: 2032-2042.

33. Hake SB, Garcia BA, Duncan EM, Kauer M, Dellaire G, et al. (2006) Expression patterns and post-translational modifications associated with mammalian histone H3 variants. J Biol Chem 281: 559-568.
34. Grant PA, Eberharter A, John S, Cook RG, Turner BM, et al. (1999) Expanded lysine acetylation specificity of Gen5 in native complexes. J Biol Chem 274: 5895-5900.

35. Morris SA, Rao B, Garcia BA, Hake SB, Diaz RL, et al. (2007) Identification of histone $\mathrm{H} 3$ lysine 36 acetylation as a highly conserved histone modification. J Biol Chem 282: 7632-7640.

36. Kikuchi H, Takami Y, Nakayama T (2005) GCN5: a supervisor in all-inclusive control of vertebrate cell cycle progression through transcription regulation of various cell cycle-related genes. Gene 347: 83-97.

37. Jin QH, Yu LR, Wang LF, Zhang ZJ, Kasper LH, et al. (2011) Distinct roles of GCN5/PCAF-mediated H3K9ac and CBP/p300-mediated H3K18/27ac in nuclear receptor transactivation. EMBO J 30: 249-262.

38. Cornish-Bowden A, Cardenas ML (2010) Specificity of non-Michaelis-Menten enzymes: necessary information for analyzing metabolic pathways. J Phys Chem B 114: 16209-16213.

39. Brot FE, Bender ML (1969) Use of the specificity constant of alphachymotrypsin. J Am Chem Soc 91: 7187-7191.

40. Bosshard HR (1976) Theories of enzyme specificity and their application to proteases and aminoacyl-transfer RNA synthetases. Cell Mol Life Sci 32: 949963

41. Hedstrom L (2001) Enzyme Specificity and Selectivity. In: eLS. John Wiley \& Sons, Ltd, Chichester.

42. Bender ML, Kezdy FJ (1965) Mechanism of action of proteolytic enzymes. Annu Rev Biochem 34: 49-76.

43. Radzicka A, Wolfenden R (1995) A proficient enzyme. Science 267: 90-93.

44. Wolfenden R (2006) Degrees of difficulty of water-consuming reactions in the absence of enzymes. Chem Rev 106: 3379-3396.

45. Truscott RJW, Mizdrak J, Friedrich MG, Hooi MY, Lyons B, et al. (2012) Is protein methylation in the human lens a result of non-enzymatic methylation by S-adenosylmethionine? Exp Eye Res 99: 48-54.

46. Commerford SL, Carsten AL, Cronkite EP (1982) Histone turnover within nonproliferating cells. Proc Natl Acad Sci U S A 79: 1163-1165.

47. Wu RS, Panusz HT, Hatch CL, Bonner WM (1986) Histones and their modifications. CRC Crit Rev Biochem 20: 201-263.

48. Schwer B, Eckersdorff M, Li Y, Silva JC, Fermin D, et al. (2009) Calorie restriction alters mitochondrial protein acetylation. Aging Cell 8: 604-606.

49. Wagner GR, Payne RM (2011) Mitochondrial acetylation and diseases of aging. J Aging Res 2011: Article ID 234875.

50. Deng LW, Wang D, de la Fuente C, Wang L, Li H, et al. (2001) Enhancement of the p300 HAT activity by HIV-1 Tat on chromatin DNA. Virology 289: 312 326.

51. Kuo MH, vom Baur E, Struhl K, Allis CD (2000) Gen4 activator targets Gen5 histone acetyltransferase to specific promoters independently of transcription. Mol Cell 6: 1309-1320.

52. Cai L, Sutter BM, Li B, Tu BP (2011) Acetyl-CoA induces cell growth and proliferation by promoting the acetylation of histones at growth genes. Mol Cell 42: 426-437.

53. Tanner KG, Trievel RG, Kuo MH, Howard RM, Berger SL, et al. (1999) Catalytic mechanism and function of invariant glutamic acid 173 from the histone acetyltransferase GCN5 transcriptional coactivator. J Biol Chem 274: 18157-18160.

54. Davey CA, Sargent DF, Luger K, Maeder AW, Richmond TJ (2002) Solvent mediated interactions in the structure of the nucleosome core particle at 1.9 angstrom resolution. J Mol Biol. 319: 1097-1113. 